OPEN ACCESS

Edited by:

Muthuraman Muthuraman, Universitätsmedizin der Johannes Gutenberg-Universität Mainz,

Germany

Reviewed by:

Pedro J. Garcia-Ruiz, Hospital Universitario Fundación Jiménez Díaz, Spain Mohamed Mosaad Salama, Mansoura University, Egypt

*Correspondence: Irene Litvan ilitvan@ucsd.edu

Specialty section: This article was submitted to Movement Disorders, a section of the journal Frontiers in Neurology

Received: 12 April 2018 Accepted: 31 May 2018 Published: 20 June 2018

Citation:

Kelley KD, Checkoway H, Hall DA, Reich SG, Cunningham $C$ and Litvan I

(2018) Traumatic Brain Injury and Firearm Use and Risk of Progressive Supranuclear Palsy Among Veterans. Front. Neurol. 9:474. doi: 10.3389/fneur.2018.00474

\section{Traumatic Brain Injury and Firearm Use and Risk of Progressive Supranuclear Palsy Among Veterans}

\author{
Kristen D. Kelley ${ }^{1}$, Harvey Checkoway ${ }^{2}$, Deborah A. Hall ${ }^{3}$, Stephen G. Reich ${ }^{4}$, \\ Chris Cunningham ${ }^{5}$ and Irene Litvan ${ }^{6 *}$
}

${ }^{1}$ School of Medicine, University of California, San Diego, La Jolla, CA, United States, ${ }^{2}$ Department of Family Medicine \& Public Health, University of California, San Diego, La Jolla, CA, United States, ${ }^{3}$ Department of Neurology, Rush University Medical Center, Chicago, IL, United States, ${ }^{4}$ Department of Neurology, University of Maryland, Baltimore, MD, United States, ${ }^{5}$ Clinical Trials Unit, University of Louisville, Louisville, KY, United States, ${ }^{6}$ Department of Neurosciences, University of California, San Diego, La Jolla, CA, United States

Background: Progressive supranuclear palsy (PSP) is a tauopathy that has a multifactorial etiology. Numerous studies that have investigated lead exposure and traumatic brain injury (TBI) as risk factors for other tauopathies, such as Alzheimer's disease, but not for PSP.

Objective: We sought to investigate the role of firearm usage, as a possible indicator of lead exposure, and TBI as risk factors for PSP in a population of military veterans.

Methods: We included participants from a larger case-control study who reported previous military service. Our sample included 67 PSP cases and 68 controls. Participants were administered a questionnaire to characterize firearm use in the military and occurrence of TBI.

Results: Cases were significantly less educated than controls. In unadjusted analyses, the proportion of PSP cases (80.6\%) and controls (64.7\%) who reported use of firearms as part of their military job was positively associated with PSP, odds ratio (OR) 2.2 (95\% $\mathrm{Cl}$ : 1-5.0). There were no significant case-control differences in mean service duration. There was only a weak association with history of TBI, OR 1.6 (95\% Cl: 0.8-3.4). In multivariate models, firearm usage (OR $3.7,95 \% \mathrm{Cl}: 1.5,9.8)$ remained significantly associated with PSP.

Conclusions: Our findings show a positive association between firearm usage and PSP and an inverse association between education and PSP. The former suggests a possible etiologic role of lead. Further studies are needed to confirm the potential etiologic effects of metals on PSP.

The study was registered in clinicaltrials.gov. ClinicalTrials.gov Identifier: NCT00431301.

Keywords: PSP, case-control study, military, firearms, traumatic brain injury 


\section{INTRODUCTION}

Progressive supranuclear palsy (PSP) is a rare neurodegenerative movement disorder, and the most common of the atypical parkinsonian disorders. Pathologically, PSP is one of the tauopathies, a group of diseases in which tau, a protein involved in stabilizing microtubules, becomes hyperphosphorylated and forms insoluble aggregates in neurons (neurofibrillary tangles, NFTs) and astrocytes (tufted astrocytes) (1). The causes of PSP are poorly understood, although, the etiology is hypothesized to be multifactorial, evidenced by research indicating etiologic contributions from genetics, and various environmental exposures (2-5).

To our knowledge, neither heavy metal exposure nor traumatic brain injury (TBI) have been investigated as risk factors for PSP. However, many studies have investigated both heavy metal exposure and TBI as risk factors for other tauopathies, including Alzheimer's disease (AD) and chronic traumatic encephalopathy (CTE) (6-10). Due to the high prevalence of TBI and increased potential risk of heavy metal exposure due to use of firearms, military veterans are an appropriate population to investigate both of these potential risk factors.

It has been well-established that the use of firearms, in both indoor and outdoor ranges, increases exposure to lead and other heavy metals $(11,12)$. Occupational exposure studies have found increased blood lead levels in individuals who regularly use firearms as part of their jobs, including police officers and firearm instructors (13-15).

The relationship between lead exposure and cognitive decline has been well-established based on numerous reports from the Normative Aging Study $(16,17)$. These findings, among other, sparked interest in investigating a potential link between lead exposure and tauopathies which commonly present with cognitive decline $(6-8,18)$. One of the earliest mentions of the potential connection between lead exposure and tauopathy actual predates these studies and was a case report published in 1975. This report described the autopsy findings of an individual who died at age 42 due to worsening of lead encephalopathy. Post-mortem examination demonstrated a tenfold increase in lead in specific areas of the patient's brain compared to health controls. On histological examination there were numerous NFTs in addition to diffuse cortical atrophy which was thus attributed to the lead exposure (18). Since this early observation, several subsequent studies have investigated the potential connection between lead exposure and tau pathology (6-8). It has been shown that early exposure to lead can, in fact, alter the tau gene and gene expression (19). Additionally, in both rodent and primate models, early exposure to lead was reported to be associated with increased levels of total tau protein and tau mRNA, as well as increased levels of hyperphosphorylated tau and an increased presence of NFTs on brain tissue $(7,8)$. Rodent knock-out models have also confirmed that the tau pathway is required for lead to effect cognitive function (20).

Another risk factor for developing tauopathies is TBI. It has been well established that experiencing TBI increases the risk of developing $\mathrm{AD}$ (21-25). Much of the research establishing this link has been in the veteran population, due to the increased prevalence of TBI in these individuals $(23,24)$. Additionally, CTE, another tauopathy, is strongly linked to TBI. CTE was first described in professional boxers, but now is being recognized in other contact sport athletes, military veterans, and other civilians. Though initially CTE was mainly thought to be caused by more severe head injuries, there is now evidence that repetitive mild trauma can lead to this pathology (10).

In this study, we sought to investigate the role of these potential risk factors for PSP that may be more prevalent within the military population. Specifically, we aimed to explore the effect of the use of firearms, which typically causes lead exposure, and head injury on the development of PSP. Based on the current literature, we hypothesized that PSP cases will be more likely to report the use of firearms in the military and having experienced TBI with and without loss of consciousness.

\section{MATERIALS AND METHODS}

\section{Participants}

This study included all male participants from a larger multicenter case control study examining environmental and genetic risk factors associated with PSP (5) who reported having served in the US military. PSP patients (i.e., cases) were recruited from 15 sites across North America. Internal Review Board approval was obtained at each participating site. All participants completed a consent form for enrollment in this study. The original study cohort included 350 PSP participants, 284 matched cases and controls have been previously reported (5). Site PIs who recruited more than seven participants for the present study were invited to be included as authors, while those who recruited fewer participants are acknowledged.

As previously reported (5), PSP cases were incident cases, diagnosed within 1 year preceding the interview by the site principal investigator (PI). Diagnosis was based on the NINDSSPSP criteria (26). Of the 67 PSP cases included in the present study, $87 \%$ met the NINDS-SPSP criteria for clinically probable or neuropathologically definite PSP. The remaining patients $(n=9)$ met criteria for clinically possible PSP. The majority of PSP cases $(n=53)$ had a Mini Mental Status Examination (MMSE) score $\geq 25$ (27). Approximately 20\% $(n=14)$ of the participants scored 24 or less on the MMSE, however, the primary site PI believed these participants did not meet criteria for major neurocognitive impairment and thus they were included.

PSP cases identified an age ( \pm 5 years) and gender matched non-blood related control, usually non-blood related in-laws. Identified controls were screened for cognitive impairment using the Telephone Interview for Cognitive Status (28) and for Parkinsonism using a telephone interview (29).

For each case, and their associated control, the reference year was defined as 10 years prior to the date of first reported PSP symptom. The purpose of this time frame was to account for the hypothesized lag time for PSP to manifest clinically. Though there is no published literature on the length of this lag time, we chose 10 years to be on the conservative side and avoid including possible preclinical and prodromal disease periods.

For the present study, we limited the analysis to cases and controls who reported having served in the military because 
of the greater prevalence of the exposures of interest. We additionally excluded women participants as there were only two women veterans in our sample. The final sample included 67 PSP cases and 68 controls.

\section{Measures}

All participants were administered a modified telephone questionnaire from Stewart assessing participant experiences in the military by trained study personnel (30). The outcomes of interest were defined as: demographics, age at time of entering service, service duration, use of a firearm while in service, indoor use of a firearm while in service, estimated total career firearm usage in hours, and occurrence of a TBI with and without loss of consciousness.

The estimate of the total firearm usage over the duration of each participant's military career was calculated using the reported monthly firearm usage estimate and service duration.

\section{Statistical Analysis}

All tests of significance were two-tailed and alpha was set as 0.05 . Statistical analysis was performed using the program "R," with the packages "epitools," "car," "dplyr," "stringr," and "gmodels" (31).

For the outcomes of interest that were continuous we estimated the means and standard deviations for PSP cases and controls, differences in means were assessed using the Student's $t$-test. For outcomes of interest that were binary we report frequencies and proportions.

For binary outcomes, we calculated conditional odds ratios (ORs) relative to the control group. We additionally calculated an adjusted OR for each measure controlling for age and highest level of education. Significance of ORs and adjusted ORs were assessed using the Chi square test.

To control for possible confounding variables after conducting the univariate analysis we then performed a multivariate conditional logistic regression analysis using only the variables with $p<0.05$ in the univariate analysis.

\section{RESULTS}

\section{Demographic Data}

There was a significant difference in the highest level of education between cases and controls, with controls being significantly more likely to report having obtained greater than a high school education compared to cases, as previously reported (5). Similarly, controls reported a significantly greater number of years of schooling when compared to PSP cases. As seen in Table 1, we found no between-group differences in the remaining demographic data, including in military specific demographics such as average age at enrollment in the military and average service duration.

\section{Firearm Usage}

We found a significant difference in proportion of participants reporting use of firearms as part of their job in the military between PSP cases (80.6\%) and controls (64.7\%), yielding an adjusted OR of 1.7 ( $p=0.04$; Table 2$)$. However, there was no significant difference in the proportion of cases and controls who
TABLE 1 | Demographic results.

\begin{tabular}{|c|c|c|c|}
\hline & Cases & Controls & Significance \\
\hline Number of subjects & $N=67$ & $N=68$ & \\
\hline Age: mean \pm SD & $71.1 \pm 7.5$ & $72.2 \pm 7.1$ & $p=0.38$ \\
\hline $\begin{array}{l}\text { Age at beginning of military } \\
\text { service: mean } \pm S D\end{array}$ & $20.4 \pm 2.6$ & $21.2 \pm 3.3$ & $p=0.09$ \\
\hline Service duration: mean \pm SD & $4.9 \pm 6.6$ & $5.4 \pm 6.7$ & $p=0.63$ \\
\hline $\begin{array}{l}\text { Marital status at reference year: } \\
\text { percent }(N)\end{array}$ & & & $p=0.12$ \\
\hline Married & $97.0 \%(65)$ & $89.7 \%(61)$ & \\
\hline Divorced & $1.5 \%(1)$ & $8.8 \%(6)$ & \\
\hline Never married & $1.5 \%(1)$ & $1.5 \%(1)$ & \\
\hline $\begin{array}{l}\text { Annual income at reference year: } \\
\text { percent }(N)\end{array}$ & & & $p=0.14$ \\
\hline Less than $\$ 50,000$ & $43.3 \%(29)$ & $26.5 \%(18)$ & \\
\hline$\$ 50,000-\$ 79,999$ & $26.9 \%(18)$ & $27.9 \%(19)$ & \\
\hline Greater than $\$ 80,000$ & $25.4 \%(17)$ & $41.2 \%(28)$ & \\
\hline Did not report & $4.5 \%(3)$ & $4.4 \%(3)$ & \\
\hline $\begin{array}{l}\text { Highest level of education: } \\
\text { percent }(N)\end{array}$ & & & $p<0.001$ \\
\hline High school education or less & $55.2 \%(37)$ & $23.5 \%(16)$ & \\
\hline $\begin{array}{l}\text { Greater than high school } \\
\text { education }\end{array}$ & $44.8 \%(30)$ & $76.5 \%(52)$ & \\
\hline $\begin{array}{l}\text { Years of schooling completed: } \\
\text { mean } \pm \mathrm{SD}\end{array}$ & $14.0 \pm 2.8$ & $16.2 \pm 3.3$ & $p<0.001$ \\
\hline Ethnicity: percent $(N)$ & & & $p=0.50$ \\
\hline White or European-American & $98.5 \%(66)$ & $100.0 \%(68)$ & \\
\hline Black or African American & $1.5 \%(1)$ & $0.0 \%(0)$ & \\
\hline $\begin{array}{l}\text { Employment at reference year: } \\
\text { percent }(N)\end{array}$ & & & $p=0.40$ \\
\hline Full-time employed & $79.1 \%(53)$ & $70.6 \%(48)$ & \\
\hline Part-time employed & $1.5 \%(1)$ & $4.4 \%(3)$ & \\
\hline Retired & $19.4 \%(13)$ & $25.0 \%(17)$ & \\
\hline \multicolumn{4}{|l|}{$\begin{array}{l}\text { Dementia screening tools: mean } \\
\pm S D\end{array}$} \\
\hline Cases-MMSE & $27.0 \pm 2.1$ & $\mathrm{~N} / \mathrm{A}$ & \\
\hline Controls-TICS & N/A & $36.5 \pm 3.5$ & \\
\hline
\end{tabular}

There was a significant difference between the highest level of education obtained and the years of schooling completed, as previously reported. There were no other between group differences. SD, Standard deviation; MMSE, Mini-Mental Status Exam; TICS, Telephone Interview for Cognitive Status.

reported indoor firearm use while in the military, OR of $0.7(p=$ $0.56)$. We found no significant difference in estimated total hours spent using a firearm in the military between PSP cases (112.9 \pm 169.8) and controls (158.6 $\pm 299.2 ; p=0.28)$.

\section{Traumatic Brain Injury}

We found that reporting having experienced a TBI was more prevalent in the PSP cases (38.8\%) compared to the controls (27.9\%). This yielded an OR of 1.6, however, this was not significant $(p=0.20$; Table 3 ). However, contrary to what we hypothesized, of those who experienced TBI, loss of consciousness was more prevalent in controls, though this difference was not significant either. 
TABLE 2 | Firearm exposure results.

\begin{tabular}{|c|c|c|c|c|c|c|}
\hline & Cases exposed: percent $(N)$ & Controls exposed: percent $(N)$ & OR $(95 \% \mathrm{Cl})$ & $P$-value & $\begin{array}{l}\text { Adjusted OR } \\
(95 \% \mathrm{Cl})\end{array}$ & $P$-value \\
\hline Use of firearm in service & $80.6 \%(54)$ & $64.7 \%(44)$ & $\begin{array}{l}2.2 \\
(1.0-5.0)\end{array}$ & 0.04 & $\begin{array}{l}1.7 \\
(0.7-4.0)\end{array}$ & $0.04^{*}$ \\
\hline Indoor use of firearm & $7.5 \%(5)$ & $10.3 \%(7)$ & $\begin{array}{l}0.7 \\
(0.2-2.4)\end{array}$ & 0.56 & $\begin{array}{l}0.7 \\
(0.2-2.5)\end{array}$ & 0.56 \\
\hline
\end{tabular}

PSP cases were significantly more likely to report use of firearm while in the service, adjusting for age and education. OR, Odds ratio; $N$, number. ${ }^{*} p \leq 0.05$.

TABLE 3 | TBI odds ratios.

Cases exposed: percent $(N)$ Controls exposed: percent $(N)$ OR $(95 \% \mathrm{CI})$

$P$-value Adjusted OR (95\% P-value Cl)

\begin{tabular}{|c|c|c|c|c|c|c|}
\hline TBI occurrence & $38.8 \%(26)$ & $27.9 \%(19)$ & $\begin{array}{l}1.6 \\
(0.8-3.4)\end{array}$ & 0.20 & $\begin{array}{l}1.8 \\
(0.8-3.9)\end{array}$ & 0.18 \\
\hline $\begin{array}{l}\text { Loss of consciousness in } \\
\text { TBl participants }\end{array}$ & $42.3 \%(11)$ & $57.9 \% \%(11)$ & $\begin{array}{l}0.5 \\
(0.2-1.8)\end{array}$ & 0.37 & $\begin{array}{l}0.7 \\
(0.2-2.5)\end{array}$ & 0.30 \\
\hline
\end{tabular}

There was a higher prevalence of reported TBI in the cases, but, this was not significant. TBI, traumatic brain injury; OR odds ratio.

\section{Multivariate Conditional Logistic Regression}

Based on the results of univariate analyses, we included having greater than a high school education and reported use of firearm in military service in the multivariate conditional logistic regression. Concordant with other studies, we found that higher education level is inversely related to the risk of developing PSP, with an OR of $0.3, p$-value of 0.01 . We additionally found that in multivariate analysis reported firearm use during military service remained a significant predictor for developing PSP, yielding an OR of $3.7, p$-value of 0.01 .

\section{DISCUSSION}

In this study we utilized a case-control study design to investigate potential risk factors for developing PSP in a military veteran population. In particular, we focused on firearm usage and reported occurrence of TBI as a risk factors for developing PSP.

We used reported firearm usage as a potential indicator of exposure to heavy metals, based on findings in the literature significant differences in blood lead levels with significant firearm use (13-15). We were interested in investigating heavy metal exposure as a potential risk factor of PSP due to the growing body of literature implicating lead in abnormal brain pathologies, in particular tau pathologies (6-10). Thus, we hypothesized that PSP patients would report greater use of firearms compared to controls. Our hypothesis was supported by the study as we found that cases were more than twice as likely to report use of firearms in their military positions compared to controls. However, we did not find differences in estimated total hours of firearm usage between cases and controls. It is likely that the binary recall of firearm use is more accurate than the estimated hours spent shooting, due to level of detail required for accurate recall. Lead and other metal exposures would be expected to be greatest in indoor firearm use environments. The very small numbers of cases (5) and controls (7) who reported indoor firearm limits interpretation of the findings. We also found, as previously reported, that higher education was associated with PSP $(5,32$, 33). More importantly, in multivariate analyses, use of firearms in the military and level of education were both significantly associated with PSP. Moreover, the usage of arms in the military may increase to almost four times the risk of developing PSP, whereas there was an inverse relation with higher education.

This is the first case-control study to demonstrate PSP is associated with exposure to firearm usage. In our main study that included 284 cases and 284 controls matched for age, gender, and race, expert-inferred exposures analysis showed that cases were more often assigned to metal non-military occupational exposures by case-status-blinded experts (5). In addition, expertinferred exposures analysis showed that PSP patients had greater but not significantly different exposures to manufacturing and mining jobs than controls (not shown). However, it is possible that statistical differences were not found due to the overall low frequency of these jobs in our sample. Moreover, a recent report of a cluster of PSP patients in France in a geographical area with severe environmental contamination by industrial metals supports the possible association with metals (34).

Our study also sought to investigate the role of TBI as a risk factor for PSP. Based on the fact that TBI has been implicated in other tauopathies, including AD and CTE, we hypothesized that PSP patients would be more likely to report head injury than controls. It is hypothesized that TBI may contribute to the development of these conditions by leading to an increase in the amount of aggregated phosphorylated tau (9, 10). Though we did find that a greater proportion of PSP cases reported head injury compared to controls there was no significant difference. However, we did not have enough power in this study to fully assess this relationship, and future studies will be needed. Additionally, participants who endorsed having experienced a head injury were asked if they had loss of consciousness at the time. This was included as a potential marker of head injury 
severity. Although not statistically significant, contrary to our hypothesis of those who experienced TBI, controls were more likely to report loss of consciousness. Again, however, there was not enough statistical power.

Our study has several limitations. One of the main limitations of our study is that we were unable to test our hypothesis that the connection between firearm usage and the risk of developing PSP was mediated via heavy metal exposure. We based our hypothesis on strong literature support demonstrating that firearm usage increases serum lead content, and that lead exposure acts on the tau pathway increasing gene expression and tau protein levels. It would have been very interesting to be able to test this hypothesis by obtaining serum lead levels on our participants. However, given our study design, along with the significant separation in time from potential exposure to lead and development of clinical PSP symptoms, this was not possible. We hope that additional studies, including potentially prospective studies, will be able to investigate this further. An additional limitation is that we have asked participants to recall information from many years in the past and thus it might not be recalled accurately. We believe many of our primary endpoints, including use of a firearm in their position while in the military and whether they have experienced a head injury are likely to be recalled accurately. However, the more specific endpoints, including estimated amount of time shooting per month, are likely more difficult to recall. There is also the concern that due to the potential effect of PSP on recall would be poorer in the cases. To control for this we included only incident PSP cases and used the MMSE to screen for cognitive impairment. Another limitation of our methodology is that we did not specifically inquire about repetitive head trauma, which is one of the mechanisms thought to contribute to the development of CTE. Focusing more on the nature of head injuries and the number of occurrences would be an interesting direction for future studies. More importantly, it would have been important to obtain the medical records of the study participants while in service to confirm the occurrence and severity of TBIs. This potentially would have allowed for a more accurate estimation of exposure to head injury. Finally, due to the relatively small sample size, our study had limited statistical power.

One of the strengths of this study is that it is the first to investigate these potential risk factors for the development of PSP and it was conducted in a population with higher exposure to these factors than the general population. In addition, the study used a validated questionnaire and uniform telephone administration to cases and controls (30). Additionally, given that PSP is such a rare disease we recruited a relatively large number of cases within the military veteran population.

In summary, our study found that in multivariate analyses, use of firearms in veterans who were in the military increases the odds of PSP, whereas higher education decreases the odds of developing this disorder. Further larger studies should confirm these results and investigate the relationship between PSP and metals, particularly when previous studies show possible association between PSP and metals.

\section{ETHICS STATEMENT}

This study was carried out in accordance with the Declaration of Helsinki. All subjects provided written informed consent prior entering the study. The protocol was approved by the IRB at each participating site.

\section{AUTHOR CONTRIBUTIONS}

IL, HC, DH, SR, and CC contributed to the conception and design of the study. KK organized the database and performed the statistical analysis, wrote the first draft of the manuscript. IL, HC, DH, SR, and CC critically revised the draft and provided updates. All authors contributed to the manuscript revision, read, and approved the submitted version.

\section{FUNDING}

This study was funded by National Institute of Aging 5R01AG024040. Additionally, the project described was partially supported by the National Institutes of Health, Grant TL1TR001443 of CTSA. The content is solely the responsibility of the authors and does not necessarily represent the official views of the NIH. KK has received funding from the National Institute of Health. $\mathrm{HC}$ has received research funding from the National Institute of Environmental Health Sciences and the National Multiple Sclerosis Society. DH has received funding from the National Institute of Health, the Parkinson Foundation, the Shapiro Foundation, Pfizer, and Neurocrine. $\mathrm{SR}$ received research funding from NIH-NINDS/ORDRNCATS. He received royalties from Informa and from being a reviewer of UpToDate. CC has no financial disclosures. IL is also an investigator in studies funded by 5P50 AG00513131, 5T35HL007491, 1U01NS086659, 1U54NS092089-01, Parkinson Study Group, Michael J Fox Foundation, AVID Pharmaceuticals, C2N Diagnostics and Bristol-Myers and Squibb. She receives her salary from the University of California San Diego. She is member of the Biotie/Michael J Fox Foundation Advisory Board and was member of the Biogen and Bristol-Myers and Squibb Advisories Boards. Dr. Riley has received honoraria from Allergan, Lundbeck, and Teva. Dr. Bordelon received speaker honoraria from Teva and Lundbeck.

\section{ACKNOWLEDGMENTS}

The authors want to thank all participants who generously gave their time to participate in this study. They also want to thank Drs. Jorge Juncos, David Standaert, Yvette Bordelon, David Riley, David Sprecht, Connie Marras, and James Leverenz for recruitment of patients. The authors would like to thank Dr. Peter Lees for significant help in the modification of the Steward questionnaire. 


\section{REFERENCES}

1. Ludolph AC, Kassubek J, Landwehrmeyer BG, Madelkov E, Madelkov E-M, Burn DJ, et al. Tauopathies with Parkinsonism: clinical spectrum, neuropatholic basis, biological markers, and treatment options. Eur J Neurosci. (2009) 16:297-309. doi: 10.1111/j.1468-1331.2008.02513.x

2. Swerdlow R, Golbe L, Parks J, Cassarino D, Binder D, Grawey A, et al. Mitochondrial dysfunction in cybrid lines expressing mitochondrial genes from patients with progressive supranuclear palsy. J Neurochem. (2000) 75:1681-4. doi: 10.1046/j.1471-4159.2000.0751681.x

3. Litvan I. Update on epidemiological aspects of progressive supranuclear palsy. Mov Disord. (2003) 18(Suppl. 6):S43-50. doi: 10.1002/mds.10562

4. Houghton D, Litvan I. Unraveling progressive supranuclear palsy: from the bedside back to the bench. Parkinson Relat Disord. (2007) 13:S341-6. doi: 10.1016/S1353-8020(08)70028-2

5. Litvan I, Lees PSJ, Cunningham CR, Rai SN, Cambon AC, Standaert DG, et al. Environmental and occupational risk factors for progressive supranuclear palsy: case-control study. Mov Disord. (2016) 3:644-52. doi: $10.1002 / \mathrm{mds} .26512$

6. Wu J, Basha MR, Brock B, Cox DP, Cardozo-Pelaez F, McPherson $\mathrm{CA}$, et al. Alzheimer's disease (AD) like pathology in aged monkeys following infantile exposure to environmental metal lead $(\mathrm{Pb})$ : Evidence for developmental origin and environmental link for AD. J Neurosci. (2008) 28:7. doi: 10.1523/JNEUROSCI.4405-07.2008

7. Bihaqi SW, Zawia NH. Enhanced taupathy and AD-like pathology in aged primate brains decades after infantile exposure to lead $(\mathrm{Pb})$. Neurotoxicology (2013) 39:95-101. doi: 10.1016/j.neuro.2013.07.010

8. Bihaqi SW, Bahmani A, Adem A, Zawia NH. Infantile postnatal exposure to lead $(\mathrm{Pb})$ enhances tau expression in the cerebral cortex of middle aged mice: relevance to AD. Neurotoxicology (2014) 44:114-20. doi: 10.1016/j.neuro.2014.06.008

9. Daneshvar DH, Goldstein LE, Kiernan PT, Stein TD, McKee AC. Posttraumatic neurodegeneration and chronic traumatic encephalopathy. Mol Cell Neurosci. (2015) 66:81-90. doi: 10.1016/j.mcn.2015.03.007

10. Gardner RC, Yaffe K. Epidemiology of mild traumatic brain injury and neurodegenerative disease. Mol Cell Neurosci. (2015) 66:75-80. doi: 10.1016/j.mcn.2015.03.001

11. Novotny T, Cook M, Hughes J, Lee SA. Lead exposure in a firing range. Am J Public Health (1987) 77:1225-6. doi: 10.2105/AJPH.77.9.1225

12. Beaucham C, Page E, Alarcon WA, Calvert GM, Methner M, Schoonover TM. Indoor firing ranges and elevated blood lead levels - United States, 2002-2013. Cen Dis Control Prevent. (2014) 63:347-51.

13. Fisher-Fischbein J, Fischbein A, Melnick HD, Barden W. Correlation between biochemical indicators of lead exposure and semen quality in a lead-poisoned firearms instructor. JAMA (1987) 257:803-5. doi: 10.1001/jama.1987.03390060093031

14. Goldberg RL, Hicks AM, O'Leary LM, London S. Lead exposure at uncovered outdoor firing ranges. J Occup Med. (1991) 33:718-9. doi: 10.1097/00043764-199106000-00013

15. Svensson B, Schütz A, Nilsson A, Skerfving S. Lead exposure in indoor firing ranges. Int Arch Occup Environ Health (1992) 64:219-21. doi: $10.1007 / \mathrm{BF} 00378278$

16. Payton M, Riggs KM, Spiro A III, Weiss ST, Hu H. Relations of bone and blood lead to cognitive function: the VA Normative Aging Study. Neurotoxicol Teratol. (1998) 20:19-27. doi: 10.1016/S0892-0362(97)00 075-5

17. Weisskopf MG, Wright RO, Schwartz J, Spiro A III, Sparrow D, Aro A, et al. Cumulative lead exposure and prospective change in cognition among elderly men: the VA Normative Aging Study. Am J Epidemiol. (2004) 160:1184-93. doi: 10.1093/aje/kwh333

18. Niklowitz WJ, Mandybur TI. Neurofibrillary changes following lead encephalopathy. J Neuropathol Exp Neurol. (1975) 34:445-55. doi: 10.1097/00005072-197509000-00006

19. Dash M, Eid A, Subaiea G, Chang J, Deeb R, Masoud A, et al. Developmental exposure to lead $(\mathrm{Pb})$ alters the expression of the human tau gene and its products in a transgenic animal model. Neurotoxicology (2016) 55:154-9. doi: 10.1016/j.neuro.2016.06.001

20. Wright K, Bihaqi SW, Lahouel A, Masoud A, Mushtaq F, Leso A, et al. Importance of tau in cognitive decline as revealed by developmental exposure to lead. Toxicol Lett. (2018) 284:63-9. doi: 10.1016/j.toxlet.2017.11.041

21. O'Meara ES, Kukull WA, Sheppard L, Bowen JD, McCormick WC, Teri L, et al. Head injury and risk of Alzheimer's disease by apolipoprotein E genotype. Am J Epidemiol. (1997) 146:373-84. doi: 10.1093/oxfordjournals.aje.a009290

22. Schofield PW, Tang M, Marder K, Bell K, Dooneief G, Chun M, et al. Alzheimer's disease after remote head injury: an incidence study. J Neurol Neurosurg Psychiatry (1997) 62:119-24. doi: 10.1136/jnnp.62.2.119

23. Plassman BL, Havlik RJ, Steffens DC, Helms MJ, Newman TN, Drosdick $\mathrm{D}$, et al. Documented head injury in early adulthood and risk of Alzheimer's disease and other dementias. Neurology (2000) 55:1158-66. doi: 10.1212/WNL.55.8.1158

24. Weiner MW, Friedl KE, Pacifico A, Chapman JC, Jaffee MS, Little DM, et al. Military risk factors for Alzheimer's disease. Alzheimers Dement. (2013) 9:445-51. doi: 10.1016/j.jalz.2013.03.005

25. Abner EL, Nelson PT, Schmitt FA, Browning SR, Fardo DW, Wan L, et al. Self-reported head injury and risk of late-life impairement and AD pathology in an AD Center cohort. Dement Geriatr Cogn Disord. (2014) 37:294-306. doi: 10.1159/000355478

26. Litvan I, Agid Y, Calne D, Campbell G, Dubois B, Duvoisin RC, et al. Clinical research criteria for the diagnosis of progressive supranuclear palsy (SteeleRichardson-Olszewski Syndrome): Report of the NINDS-SPSP International Workshop. Neurology (1996) 47:1-9. doi: 10.1212/WNL.47.1.1

27. Folstein MF, Folstein SE, and McHugh PR. "Mini-Mental State": a practical method for grading the cognitive state of patients for the Clinician. J Psychiatr Res. (1975) 12:189-98. doi: 10.1016/0022-3956(75)90026-6

28. Duff K, Tometich D, Dennett K. The modified telephone interview for cognitive status is more predictive of memory abilities than the minimental state examination. J Geriatr Psychiatry Neurol. (2015) 28:193-7. doi: 10.1177/0891988715573532

29. Rocca WA, Maragonore DM, McDonnell SK, Schaid DJ. Validation of a telephone questionnaire for Parkinson's disease. J Clin Epidemiol. (1998) 51:517-23. doi: 10.1016/S0895-4356(98)00017-1

30. Stewart P, Steward W, Heineman E, Dosemeci M, Linet M, Inskip P. A novel approach to data collection in a case-control study of cancer and occupational exposures. Int J Epidemiol. (1998) 25:744-52. doi: 10.1093/ije/25.4.744

31. R Core Team. R: A Language and Environment for Statistical Computing. Vienna: R Foundation for Statistical Computing (2015).

32. Golbe LI, Rubin RS, Cody RP, Belsh JM, Duvoisin RC, Grosmann C, et al. Follow-up study of risk factors in progressive supranuclear palsy. Neurology (1996) 47:148-54. doi: 10.1212/WNL.47.1.148

33. Vidal JS, Vidailhet M, Derkinderen P, de Gaillarbois TD, Tzourio C, Alperovitch A. Risk factors for progressive supranuclear palsy: a casecontrol study in France. J Neurol Neurosurg Psychiatry (2009) 80:1271-4. doi: 10.1136/jnnp.2008.149849

34. Caparros-Lefebvre D, Golbe LI, Deramecourt V, Maurage CA, Huin $\mathrm{V}$, Buee-Scherrer V, et al. A geographical cluster of progressive supranuclear palsy in northern France. Neurology (2015) 85:1293-300. doi: 10.1212/WNL.0000000000001997

Conflict of Interest Statement: The authors declare that the research was conducted in the absence of any commercial or financial relationships that could be construed as a potential conflict of interest.

Copyright (c) 2018 Kelley, Checkoway, Hall, Reich, Cunningham and Litvan. This is an open-access article distributed under the terms of the Creative Commons Attribution License (CC BY). The use, distribution or reproduction in other forums is permitted, provided the original author(s) and the copyright owner are credited and that the original publication in this journal is cited, in accordance with accepted academic practice. No use, distribution or reproduction is permitted which does not comply with these terms. 